\title{
Skene Gland
}

National Cancer Institute

\section{Source}

National Cancer Institute. Skene Gland. NCI Thesaurus. Code C61122.

A gland located in the anterior wall of the vagina that drains into the urethra at the opening. 